\title{
O ensino de geologia como instrumento formador de uma cultura de sustentabilidade
}

\author{
Joseli Maria Piranha' \& Celso Dal Ré Carneiro ${ }^{2}$
}

\begin{abstract}
Resumo A disciplina Ciência do Sistema Terra ocupa um lugar particular dentro das Ciências Naturais. Constitui área do conhecimento essencial na compreensão do equilíbrio e da complexidade do Sistema Terrestre, do qual todos dependemos. Neste contexto, preconiza-se que uma melhor integração das Ciências da Terra nos diversos sistemas educativos pode contribuir para a formação de cidadãos informados, participativos e comprometidos com a gestão responsável do planeta e seus recursos. O papel da educação científica, notadamente em Ciências da Terra, constitui instrumento fundamental de uma educação para a sustentabilidade. A iniciativa sugere profundas reorientações nos sistemas educativos vigentes e desafia os educadores a implementar abordagens educativas inovadoras, que não se confinem ao conhecimento substantivo de Geociências, mas que permitam dotar os cidadãos de valores e competências necessárias para um modo de vida sustentável. O módulo Geo-Escola São José do Rio Preto evidenciou que o emprego desses recursos, no tratamento de conteúdos de Ciências do ensino formal, constitui mediação pedagógica valiosa para desenvolver, no indivíduo, uma postura comprometida com a sustentabilidade. Em paralelo, ao se promover maior interação com professores, revelamse oportunidades promissoras de difusão das Geociências.
\end{abstract}

Palavras-chave: Educação, Geologia, Ciência do Sistema Terra, cidadania, educação básica, sustentabilidade.

\begin{abstract}
Geology teaching as a tool for developing a culture of sustainability. The Earth System Science discipline occupies a particular place within the Natural Sciences, as an essential area of knowledge for understanding the balance and complexity of the Earth System, from which we all depend. In this context, improving the integration of Earth Sciences in the various educational systems can help the formation of informed citizens, more involved and committed to a responsible management of the planet and its resources. The role of science education, particularly in Earth Sciences, is a fundamental tool to education for sustainability. The initiative points out for the need of deep changes in the existing education systems; it defies the educators to improve their educational approaches as well. It allows citizens to value and to develop skills needed for a sustainable way of life. The module Geo-School Sao Jose do Rio Preto showed that for education in schools these resources when adopted for developing contents of Sciences can reach a differentiated educational practice, which is useful to develop citizenry. In parallel, while promoting greater interaction with teachers, there are promising opportunities for the dissemination of Geosciences.
\end{abstract}

Keywords: Education, Geology, Earth System Science, citizenry, basic education, sustainability.

INTRODUÇÃo A contribuição das Geociências na formação de uma Cultura de Sustentabilidade tem sido reforçada em diferentes oportunidades. A própria definição do Ano Internacional do Planeta Terra (Berbert 2007, Figueiredo 2007) é sinal afirmativo de que o conhecimento da Ciência do Sistema Terra constitui embasamento cada vez mais necessário na formação dos cidadãos.

Diversos autores assinalam a necessidade de envolvimento mais efetivo da própria pesquisa em educação em ciência na formação das pessoas em geral. Em diferentes contextos, estudos revelam embaraços para que a educação contribua na construção de cidadania, entendida como "participação total na fixação do sentido da vida coletiva e na deliberação acerca do destino comum da sociedade" (Valle 2000, p. 26). Aspecto fundamental para a sustentabilidade, a educação do cidadão deve capacitar os indivíduos para a participação na tessitura social, de forma motivada e competente, assumindo responsabilidades quanto aos interesses e destino da coletividade.

A idéia de desenvolvimento sustentável, construída como uma "situação de justiça social, para toda a humanidade, onde o desenvolvimento sócio-econômico seria atingido em harmonia com os sistemas de suporte da vida na Terra" (Cordani 2000), convida à reflexão e reforma dos modelos e paradigmas de desenvolvimento e ainda de comportamento humano.

No âmbito da "Sociedade do Conhecimento" (no sentido proposto por Adam Schaff 1995), os avanços da Ciência, a facilidade de acesso em tempo real e a

1 - UNESP, Instituto de Biociências, Letras e Ciências Exatas, Depto. Química e Ciências Ambientais, São José do Rio Preto (SP), Brasil. E-mail: joseli@ibilce.unesp.br

2 - Universidade Estadual de Campinas, Instituto de Geociências, Depto. Geociências Aplicadas ao Ensino, Campinas (SP), Brasil.

E-mail: cedrec@ige.unicamp.br 
rapidez com que as informações são veiculadas denunciam os impactos da presença humana no planeta. Ao mesmo tempo, são capazes de tornar as pessoas mais cientes de sua natureza terrena. A velocidade dos avanços científicos, tecnológicos e culturais introduz mudanças conceituais na humanidade do século XXI.

Nesse contexto, a Década das Nações Unidas da Educação (Literacy), 2003-2012, expressa uma vontade coletiva da comunidade internacional na promoção de um ambiente literado para todos, tanto nos países desenvolvidos como nos países em desenvolvimento. Para alcançar os objetivos e propósitos da Década da Educação a UNESCO criou, como estratégia global e mecanismo operacional, uma campanha de 10 anos de ação colaborativa - a Literacy Initiative For Empowerment (LIFE) (UNESCO 2006). Dentre outras estratégias a campanha destaca a importância de inovar. As políticas e práticas educacionais inovadoras implicam tanto o suporte às práticas de qualidade existentes, como o acesso à informação e construção de um novo conhecimento.

Em justa sintonia, tem-se desenvolvido investigações relativas à importância do ensino de Ciência do Sistema Terra, com a finalidade de explorar a relação homem-natureza, buscando respostas práticas sobre a utilidade e efetividade dos conhecimentos de Geociências para formação de cidadãos cultos do ponto de vista da ciência. Com esse propósito, o Projeto GeoEscola (Carneiro \& Barbosa 2005, Carneiro et al. 2007), desenvolvido na forma de módulos regionais, disponibiliza material didático a professores de educação básica, compreendendo informações geológicas, imagens e mapas de uma dada região. O projeto fomenta o uso do computador no ensino, permitindo explorar sobretudo a linguagem visual, fortemente vinculada ao raciocínio geológico, com base nos quais os alunos podem formar uma idéia acerca dos mecanismos evolutivos do planeta e da permanente interação entre as esferas terrestres. Os materiais e recursos produzidos nos diversos módulos do Projeto valorizam procedimentos metodológicos típicos das Geociências e da Geologia, e estimulam a interpretação e a imaginação.

O módulo Geo-Escola desenvolvido em São José do Rio Preto (SP) (Piranha \& Carneiro no prelo) evidenciou que o emprego desses recursos no tratamento de conteúdos do ensino formal constitui diferenciada mediação pedagógica, valiosa para desenvolver, no indivíduo, uma postura cidadã, comprometida com a sustentabilidade (Piranha 2006). Pode-se assim aquilatar o alcance dos trabalhos educacionais na formação da cultura profissional docente e, simultaneamente, avaliar sua influência em mudanças de comportamento individual e comunitário dos educandos (Piranha \& Carneiro 2007).

Neste artigo serão focadas algumas afinidades dos referenciais teóricos da investigação realizada no âmbito do Modulo São José do Rio Preto do Projeto Geo-Escola (Fig. 1), com questões de interesse educacional para o fomento de uma cultura de sustentabilidade.

Objetivos A carência de conceitos geológicos e geocientíficos na população constitui barreira quase intransponível à capacitação do indivíduo para opinar, decidir, escolher e influir em uma série de decisões adotadas pela comunidade para se desenvolver. Assim, o interesse por analisar o alcance de práticas educativas para formação de uma cultura de sustentabilidade leva a investigar a pertinência dos conhecimentos geológicos para promoção de mudanças de costumes, atitudes e valores nos educandos, no processo de ensino-aprendizagem.

Sem pretender discutir questões relativas ao antropocentrismo, importa considerar a noção de responsabilidade que compete ao indivíduo, como agente transformador.

Considerando-se que o saber científico é inerente à natureza humana, entende-se que formar cidadãos cientificamente cultos significa possibilitar que os indivíduos agreguem tal conhecimento aos saberes cotidianos que os constituem. Busca-se aqui tratar de al-

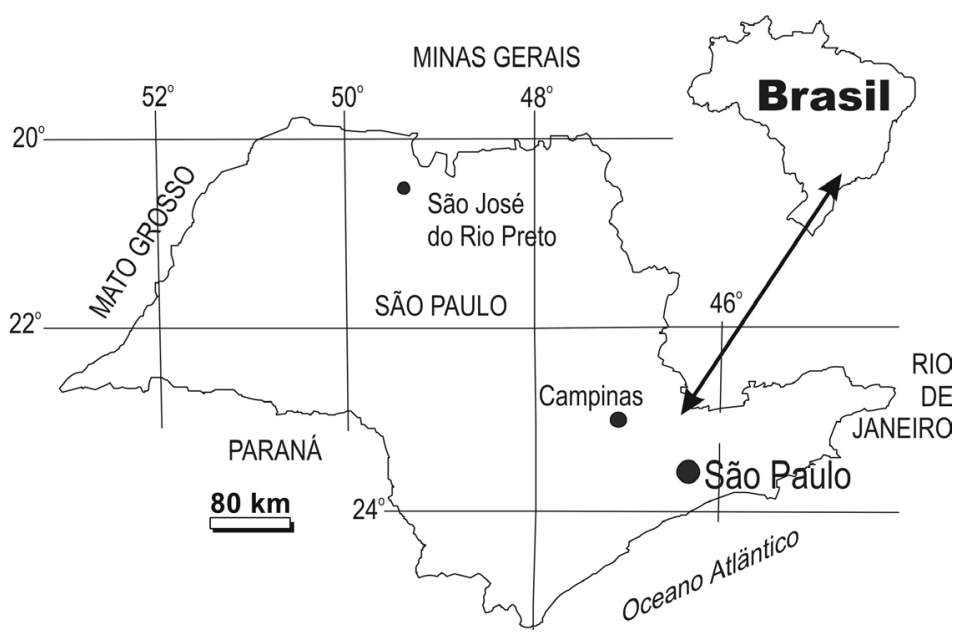

Figura 1 - Mapa de localização do município de São José do Rio Preto. 
gumas contribuições próprias do ensino-aprendizagem de Geologia, capazes de contribuir para a promoção de reflexões e de mudanças, individuais e coletivas, que favoreçam a sustentabilidade.

\section{A NATUREZA SISTÊMICA DA GEOLOGIA COMO INTEGRADORA DO ENSINO DE CIÊN-}

CIA A Geologia, a "ciência histórica da natureza" (Potapova 1968), ao ocupar-se do entendimento dos materiais, processos e produtos da evolução planetária em suas múltiplas relações, estabelece interfaces sistêmicas com os ramos das Geociências. Modernamente denominada Ciência do Sistema Terra, integra as diferentes esferas em que a matéria se organiza e nas quais todas as formas de energia provocam mudanças à medida que são permutadas. Esta condição permite, de forma peculiar,reconhecer o significado da ação humana no planeta, o que parece ser, no momento, questão central da idéia de sustentabilidade.

Assim, a Ciência do Sistema Terra busca abranger e compreender as relações entre as esferas rochosas e as demais esferas do planeta (atmosfera, hidrosfera, biosfera, tecnosfera). Nesse contexto, a partir da década de 1990, a abordagem geológica trouxe nova luz à história da Terra, na medida em que permite examinar os processos terrestres como um todo e em suas partes, conforme registrados na organização, disposição e composição das esferas rochosas.

Tal convergência de tendências abriu amplo campo de pesquisa integrada que considera a Terra como um todo. Temas tipicamente geológicos como a teoria da Tectônica de Placas e geologia planetária passaram a ser associados aos processos atuais da atmosfera e hidrosfera, para reconceituar os impactos ambientais e os acidentes naturais. Nesse modo realista de ver a ciência, que enfatiza aspectos éticos, filosóficos e históricos, diversos problemas gerais do ambiente e temas como mudança climática global e desafios globais relacionados com a sustentabilidade da vida, são tratados como diferentes aspectos da interação dinâmica do homem com o planeta.

$\mathrm{O}$ aprofundamento da crise ambiental, muitas vezes contestado (ver p. ex. Sowell 2007), põe em risco a preservação da espécie humana e seu nível atual de civilização, requerendo tratamento interdisciplinar dos problemas e aprofundamento dos estudos nas diversas áreas de conhecimento. Isso revela a clara necessidade de uma atitude ética frente à sociedade e à natureza, para "contemplar os direitos e as potencialidades do homem para interagir com a natureza" (Carneiro et al. 2005).

A perspectiva de estudo da Ciência do Sistema Terra procura dar importância aos ciclos biogeoquímicos da natureza (Mackenzie \& Mackenzie 1995), ao tratar processos das esferas naturais. A visão sistêmica, apoiada em elementos aplicados da Geologia, ajuda a explicar os padrões dinâmicos dos processos naturais. Frodeman (2000) destaca que o uso do termo geologia (do grego, Gé ou Gaia) permite abarcar o conceito de Terra-mãe, fonte da vida ou o "planeta que nós chamamos de lar", evidenciando os vínculos da vida à matéria planetária.
Em paralelo e provavelmente sem conexão direta com tal conhecimento, mas relacionadas a um crescimento da consciência ambiental, alterações de toda ordem começam a surgir, aqui e ali, e acabam por permear as comunidades humanas, nos diferentes continentes. Fenômenos relacionados à ação das sociedades tornamse relevantes na abordagem sistêmica da biosfera, como a mudança climática global, alterações do efeito estufa, precipitação ácida, degradação do solo etc. Aspectos regionais podem exemplificar fenômenos e transformações e passam a fazer parte da abordagem global.

Formar um cidadão responsável e sensível às questões afetas à Vida e ao planeta pode advir de uma educação que permita ao indivíduo reconhecer o que é o planeta, como ele funciona e como, nesse espaço e ao longo do tempo, se processam as relações da Vida. São estes alguns atributos singulares da Geologia - que concebe de forma sistêmica a entidade planetária e seus habitantes. Tal corpo de conhecimentos, somados à noção de globalização, facilita que o indivíduo reconheça sua identidade/cidadania terrena, entendendo-se por cidadão terreno o indivíduo responsável pelo uso e ocupação do meio natural e sensível aos problemas ambientais e à importância da Vida (Morin \& Kern 2002).

Em atenção à importância da formação de cidadãos cientificamente cultos, Cachapuz et al. (2002, p. 61) estudaram contributos epistemológicos, da história da ciência e da psicologia da aprendizagem em transposição para o campo da educação em ciência, e concentraram a atenção na "busca e apropriação crítica de elementos fundamentadores de uma teorização para a educação em ciências, por sua vez, também ela capaz de orientar práticas educacionais".

Com tais pressupostos e em atenção ao quadro de emergência planetária com que se depara a humanidade (Praia et al. 2007), cumpre considerar o alcance do ensino da Geologia por uma sociedade mais culta e atenta à idéia da sustentabilidade, como novo paradigma de desenvolvimento.

\section{CIÊNCIA DO SISTEMA TERRA COMO BASE DA EDUCAÇÃO VOLTADA PARA A SUSTENTA- BILIDADE}

Sustentabilidade Princípio difundido juntamente com a idéia de globalização, a sustentabilidade emerge do século XX como uma ordem ou conduta humana voltada para a permanência da vida no planeta.

Reuniões, documentos, tratados e programas internacionais ressaltam a importância dessa concepção (Cordani 1995); entretanto, o histórico evolutivo do conceito de sustentabilidade é marcado por crescente entendimento da estreita dependência entre os constituintes geológicos e a evolução da vida no planeta.

Os seres humanos "dispõem do poder de decisão e a capacidade tecnológica para parar e reverter os impactos individuais e coletivos do homem sobre a Terra" (Williams Jr. 2000). Em oposição às extinções em massa naturais ocorridas no passado terrestre, a mais recente delas, que atualmente se processa, pos- 
sui causas definitivamente relacionadas às modificações humanas da geosfera e da biosfera (Carneiro \& Gonçalves 2006).

O ensino de Geologia/Geociências pode e deve participar desse processo formador de uma cultura de sustentabilidade. Ele deve beneficiar-se até mesmo do recurso das representações, termo que implica "um tipo de exibição teatral destinada a fazer ver e a fazer valer um certo modo de ver" (Bordieu 2003, p. 33).

Uma maior atenção ao funcionamento dos processos naturais pode sugerir maior atenção à sustentabilidade da vida e assim, estimular o desenvolvimento de uma cultura planetária inovadora que, ao compreender e dimensionar o planeta em seus constituintes físicos e nos processos que os promovem e sustentam, incorpore a compreensão da vida (e, nesta, do humano) como elemento natural e indispensável ao incessante equilíbrio dinâmico da matéria planetária. Uma cultura que evidencie quão terrenos somos.

Ao se conceber terreno, o ser humano pode mudar, inovar e reconstruir idéias e paradigmas. Pode ainda entender-se responsável pela desconstrução de modelos que reconhece impróprios, e se lançar ao insuperável propósito de construir seu lugar em um futuro desejável (Morin 2003). Dessa ação pode resultar o esboço de novos caminhos para a vida.

Visão Planetária e a Cultura Científica A visão sistêmica da Ciência da Terra permite excepcional aproximação do conceito de sustentabilidade aos princípios da Educação, ao destacar a pertinência dos saberes científicos à condição humana e planetária.

Esta evolução do conhecimento científico, reflexo do atual contexto social, tecnológico e ambiental, permite compartilhar as preocupações e valores expressos na Declaração da Conferência Mundial sobre a "Ciência para o século XXI: um novo compromisso" (UNESCO 1999, apud Cachapuz et al. 2002), bem como no "Project 2061" em sua primeira versão, entitulada "Science for All Americans", organizada pela American Association for the Advancement of Science (AAAS 1989) e ainda nos "Parâmetros Curriculares Nacionais para o Ensino Médio" (Brasil 1999), em alguns aspectos que interessa ressaltar:

SOBRE O FUNCIONAMENTO DO UNIVERSO E DOS SERES VIVOS (a) Considera-se um sistema todo conjunto de elementos materiais ou ideais, entre os quais se possa encontrar ou definir alguma relação. Assim, o universo tem uma organização sistêmica, expressa em seu todo e em suas partes; (b) A vida na Terra mantém-se fundamentalmente por meio de transformações e fluxos de energia. O complexo funcionamento dos organismos vivos, e até mesmo a interdependência de diferentes espécies, obedecem, na qualidade de sistemas naturais, aos princípios físicos de conservação e transformação de matéria e energia; (c) O moderno conceito de evolução oferece um princípio unificante para entender a história da vida na Terra, as relações entre os seres vivos e a dependência da vida ao ambiente físico.
SOBRE CIÊNCIA, COMUNICAÇÃO E MÉTODO CIENTÍFICO (a) A ciência presume que as coisas e os acontecimentos no universo ocorrem em padrões consistentes, que podem ser compreendidos por meio do estudo cuidadoso e sistemático. Por intermédio do intelecto e com o auxílio de instrumentos que estendam os sentidos, as pessoas podem descobrir registros em toda a natureza; (b) A investigação científica e o uso do conhecimento científico devem respeitar os direitos humanos e a dignidade humana; (c) A contribuição da ciência é indispensável à causa da paz, do desenvolvimento e à segurança mundial; (d) A ciência é algo mais que um corpo de conhecimentos e uma forma de acumular e validar esse conhecimento. Também é uma atividade social que incorpora valores humanos; (e) As pessoas comunicam-se com freqüência, ainda que nem sempre com precisão. A comunicação implica um meio de representar a informação, meios para transmiti-la e recebê-la e ainda certa garantia de fidelidade entre o que se manda e o que se recebe. A Educação deve assegurar-se disso para comunicar o saber científico.

SOBRE EDUCAÇÃO E O HOMEM (a) O ensino de ciências deve ir além da sala-de-aula, na educação formal ou não-formal, em processo de educação permanente, ou de desenvolvimento continuado do saber; (b) Dentre as finalidades da Educação Básica, destaca-se o "pleno desenvolvimento do educando, seu preparo para o exercício da cidadania" e "aprimoramento como pessoa humana, incluindo a formação ética e o desenvolvimento da autonomia intelectual e do pensamento crítico" (Brasil 1999); (c) O ensino deve ser "útil à vida e ao trabalho, no qual as informações, o conhecimento, as competências, as habilidades e os valores desenvolvidos sejam instrumentos reais de percepção, satisfação, interpretação, julgamento, atuação, desenvolvimento pessoal ou de aprendizado permanente" (Brasil 1999).

Tais concepções destacam a importância da ciência, da educação em ciência e especialmente do ensino de ciências, na formação humana - desde o ser individual ao ser coletivo. Ressaltam o caráter singular da educação como elemento de maturação social e de formação de cidadãos. Cumpre lembrar que é no conceito de cidadania que a responsabilidade individual se conjuga ao coletivo da população e denota o poder criativo do homem.

\footnotetext{
"Não é por decreto que os homens se transformam em cidadãos: é preciso que tenham interiorizado o valor democrático, que tenham descoberto seu poder criador, a força instituinte do poder criador coletivo. É preciso que sejam capazes de considerar como sua tarefa mais essencial construir e reconstruir o que deve ser a sociedade, o que deve significar justiça, igualdade, democracia, cidadania para sua sociedade" (Valle 2000: 30).
}

\section{Contribuições do conhecimento da Ciência do Siste-} ma Terra ao currículo de Ciências Uma mudança curricular do ensino de ciências na educação básica, em nível mundial, deveria ser baseado no objeto de estudo 
de todas as disciplinas de ciências - "o Sistema Terra e seu ambiente no espaço" (Mayer 2002).

A visão sistêmica do planeta, ao permitir a identificação das diferentes esferas em que a matéria planetária se organiza, esclarece as inter-relações desenvolvidas pelos constituintes destas esferas ao longo do Tempo Geológico. Essa abordagem dinâmica permite "explorar uma visão holística do planeta" (Anguita 1994), fundamental para a compreensão deste e da vida, desde os primórdios de sua formação, no presente e num futuro incerto. A perspectiva holística, que a Ciência do Sistema Terra proporciona, constitui "autêntica plataforma para a ciência integrada" e potencial facilitadora da "compreensão do desenvolvimento do conhecimento ambiental" e da "construção de um conhecimento do método científico: hipótese - observação - conclusão" (Orion 2001).

As dimensões de tempo e espaço também constituem importante diferencial proporcionado pelo ensino de Geociências (Compiani 2005), que permitem aos estudantes o desenvolvimento de "habilidades cognitivas essenciais e de visão espacial, na medida em que envolve as dimensões locais, regionais e planetárias do espaço".

O caráter interdisciplinar da geologia, que emerge da compreensão da Terra como um sistema complexo e dinâmico, ressalta a responsabilidade que recai sobre os geocientistas, os que possuem o conhecimento principal dos problemas que afligem o planeta:

(...) são eles portanto que têm a responsabilidade de fazer chegar aos detentores de poder, aos legisladores, aos educadores, bem como às comunidades em geral, a sua visão, e as possíveis propostas para enfrentar os desafios relacionados com o ambiente em que vivemos, e com o desenvolvimento sócio-econômico regional" (Cordani 2000, p. 34).

A educação em ciências contextualizada por meio do ensino da Ciência do Sistema Terra emerge como valioso instrumento para construção de uma cultura voltada para a paz mundial. Esta condição singular do conhecimento da geologia para a formação e a preparação de cidadãos e cidadãs capazes de participar de decisões fundamentadas, exige dos educadores uma adequada percepção destes problemas e uma visão global da situação de emergência planetária.

Entende-se que à Ciência do Sistema Terra cabe, em grande parte, o compromisso elementar de ampliar e difundir os conhecimentos relativos aos recursos naturais da Terra. O conhecimento dos constituintes geológicos do meio físico e dos processos geológicos fornece bases para implementação de práticas de desenvolvimento sustentável, no tocante ao uso de recursos naturais e apropriação do espaço disponível. De maneira crescente, a difusão destes conhecimentos tem dado suporte ao desenvolvimento de outros ramos da ciência (biologia, física, engenharias, arquitetura, geografia, medicina, agricultura, dentre outros); tem apoiado ainda a evolução das medidas de uso, controle, recuperação e melhor aproveitamento ou explotação sustentável dos recursos do meio físico.
Assim é que se reconhece Ciência do Sistema Terra como uma ciência integradora das demais ciências naturais, e com enorme poder articulador destas com as ciências humanas. Tais características permitem tratá-la como elemento ímpar para a construção de um sistema educacional inovador e necessário para a humanidade nesse milênio.

A educação por uma cultura de sustentabilidade A identificação de um objetivo comum para a educação dos indivíduos pode constituir estratégia aglutinadora de interesses, culturas e práticas, tão diversificadas quanto complexas, em torno da sustentabilidade da vida. $\mathrm{O}$ ato de educar para a sustentabilidade, assumido como um processo complexo, deve ser balizado por um conjunto de estratégias fundamentais.

\footnotetext{
"O conhecimento que se transmite, que se comunica, pressupõe em si alguma universalidade, a existência de algo que os indivíduos diferentes possuem em comum. No entanto, antes mesmo de poder ensinar, o sujeito vive uma experiência peculiar na construção do seu conhecimento: seu saber tem sempre as marcas e limitações que lhe são impostas pelas condições singulares em que foi adquirido" (Konder 2001: 25).
}

As palavras acima soam inspiradoras ao chamar a atenção para algo que a humanidade compartilha: a Terra.

Tratar do ensino da Ciência do Sistema Terra como estratégia no processo educacional permite avançar no reconhecimento do quê-fazer responsável que a educação, como prática de liberdade (Freire 1992, p. 94) exige.

"A consciência do mundo, que me possibilita apreender
a realidade objetiva, se alonga em consciência moral do
mundo, com que valoro ou desvaloro as práticas reali-
zadas no mundo contra a vocação ontológica dos seres
humanos ou em seu favor" (Freire 1992, p. 94).

Ao refletir sobre a condição humana e a "ameaça de autodestruição", Morin (2002, p. 114) evidencia responsabilidades individuais e coletivas:

"A Humanidade deixou de constituir uma noção ape-
nas biológica e deve ser, ao mesmo tempo, plenamente
reconhecida em sua inclusão indissociável na biosfe-
ra; a Humanidade deixou de constituir uma noção sem
raízes: está enraizada em uma "Pátria", a Terra, e a
Terra é uma Pátria em perigo. A Humanidade deixou
de constituir uma noção abstrata: é realidade vital, pois
está, doravante, pela primeira vez, ameaçada de morte;
a Humanidade deixou de constituir uma noção somente
ideal, tornou-se uma comunidade de destino, e somente
a consciência desta comunidade pode conduzi-la a uma
comunidade de vida; a Humanidade é, daqui em diante,
sobretudo, uma noção ética: é o que deve ser realizado
por todos e por cada um" [Grifos do original].

Formar indivíduos responsáveis é tarefa atual para todas as sociedades. Tais responsabilidades só po- 
dem advir se houver cuidado e atenção na formação cultural dos indivíduos e, por extensão, das coletividades.

Não obstante se reconheça que, mais do que um conjunto de valores que devem ser defendidos ou idéias que devam ser promovidas, a cultura tem hoje a conotação de um trabalho que deve ser realizado em toda a extensão da vida social (Certeau 2001); é evidente que, ao reconhecer o valor intrínseco do conhecimento de Ciência do Sistema Terra, se considere imprescindível dedicar especial atenção à gestão e transmissão dos saberes na escola, conforme destaca Forquim (1993: 28):

\footnotetext{
"A escola não é apenas, com efeito, um local onde circulam fluxos humanos, onde se investem e se geram riquezas materiais, onde se travam interações sociais e relações de poder; ela é também um local - o local por excelência nas sociedades modernas - de gestão e de transmissão de saberes e símbolos".
}

O desafio de uma educação para a cidadania e a sustentabilidade é evidente e respalda-se nas complexas realidades presentes em três níveis: na escola, como ambiente mais favorável ao ensino/aprendizagem, na família, um ambiente formador de valores afetivos e na sociedade, um ambiente de integração de diferentes indivíduos por uma causa comum. A própria complexidade é uma evidência de que o "educar para a cidadania" se faz necessário. Freire (1992, p. 90) ao considerar as complexas relações sociais, destaca a importância de uma educação diferenciada, somente possível sob um clima de rigor ético "a ser criado com necessárias e urgentes transformações sociais e políticas".

Nesse contexto, as sociedades têm reconhecido a escola como o local onde se dá a produção e (re)construção de saberes, onde as soluções para os conflitos cotidianos devem ser geradas, ensinadas e aprendidas. $\mathrm{Na}$ escola, os saberes científicos, eruditos e cotidianos são tratados, sob mediação didática, e assim se tornam ensináveis, assimiláveis (Lopes 2001) e efetivos, então, por meio do processo de ensino-aprendizagem. Diante de tamanha responsabilidade, é sempre atual a preocupação com a qualidade do trabalho educativo na instituição escolar. Perrenoud (1999, p. 32-33) reconhece a necessidade de "transformações dos programas, das didáticas, da avaliação, do funcionamento das classes e dos estabelecimentos, do ofício de professor e do ofício de aluno", no contexto de mudanças do processo educacional. As transformações despertam resistências passivas ou ativas de "todos aqueles a quem a ordem gerencial, a continuidade das práticas ou a preservação das vantagens adquiridas importam muito mais do que a eficácia da formação" (Perrenoud op. cit.).

Reconhecer tais resistências não significa que seja preciso atrelar-se a elas, de tal forma que se inutilize qualquer esboço de ação para modificá-las. Ao contrário, é preciso vencer adversidades e encontrar, pelo próprio desenvolvimento do saber, uma condição cultural mais favorável. Nesse sentido, Rios (2002, p. 39) adverte que:

"Devemos então considerar que a idéia de crise aponta para duas perspectivas - a de perigo e a de oportunida$d e$. Se consideramos apenas o perigo, corremos o risco de nos deixarmos envolver por uma atitude negativa, ignorando as alternativas de superação. É importante considerar a perspectiva de oportunidade, que nos remete à crítica, como um momento fértil de reflexão e de reorientação da prática".

Entende-se que, por compreender e assimilar a perspectiva das oportunidades, que todo momento crítico oferece, os especialistas em educação têm sustentado a busca da qualidade na evolução do trabalho educativo.

\begin{abstract}
“(...) a cultura escolar é um conjunto particular de ênfases e omissões, sujeito a grandes variações históricas, por ser fruto de um processo de seleção de uma cultura maior, seleção essa que é constantemente reinterpretada, constantemente feita e refeita" (Lopes 2001, p. 34).
\end{abstract}

Depreende-se portanto que currículo, conhecimento e cultura constituem construções sociais, cujo pano de fundo se faz, indiscutivelmente, nas relações estabelecidas entre conteúdo do ensino e relação pedagógica.

\section{A EXPERIÊNCIA EDUCACIONAL DO PROJE- TO GEO-ESCOLA EM SÃO JOSÉ DO RIO PRE-}

TO Partindo-se dos pressupostos teóricos acima, buscou-se na investigação desenvolvida com os professores da educação básica do município de São José do Rio Preto, experimentar, com base nos recursos do projeto Geo-Escola, a importância e o significado do uso dos conhecimentos geológicos e da informação geológica local para um ensino diferenciado de ciências.

Os conceitos de Geociências foram tratados sob a perspectiva integradora da Ciência do Sistema Terra, buscando-se ressaltar os vínculos e as relações que se estabelecem entre os componentes bióticos e abióticos do planeta, ao longo do tempo.

As abordagens conceituais e teóricas foram desenvolvidas com forte vinculação ao uso de informações geológicas locais e regionais, propiciando a contextualização do ensino à realidade do município, região e Estado onde vive a comunidade escolar. Neste sentido pode-se utilizar amplo banco de dados - mapas, fotografias, dados inventariados em Diagnóstico GeoAmbiental do Município (Piranha et al. 2004) - como fonte de informação e ilustração da geologia e do desenvolvimento ocorrido no município e região. Estes referenciais permitiram que todas as apresentações informatizadas, utilizadas para o ensino do conteúdo de Ciências do Sistema Terra, ganhassem a condição de representarem o ambiente onde vive a comunidade de aprendizagem. Isso possibilitou demonstrar a pertinência ao objeto de estudo, ao mesmo tempo em que convidou os aprendizes ao exercício de reflexões sobre a importância, o significado e o alcance das responsabilidades individuais e coletivas que lhes compete, na condição de agentes do desenvolvimento ocorrido.

Tais estratégias permitiram aos professores 
participantes o reconhecimento de relações sistêmicas existentes entre os indivíduos e o meio físico e ainda os mecanismos de intervenção, controle, regulação, gestão, interação positiva ou negativa que estas potenciam. Permitiu o reconhecimento da interdependência existente entre os constituintes do meio físico geológico e os organismos, ao longo do tempo, destacando a importância do conhecimento científico para a compreensão da evolução do planeta e da vida neste.

O convite ao exercício de compreensão dos mecanismos diversos que sustentam a condição de equilíbrio dinâmico, que se opera a todo tempo no planeta, levou a que os professores participantes relativizassem valores, condutas e oportunidades. As reflexões promovidas pelos mecanismos de ensino-aprendizagem possibilitaram mudanças comportamentais, e assim puderam ser concretizadas dentro do próprio grupo de participantes e para além deste, nas relações estabelecidas pelos educandos e suas comunidades de origem.

Uma vez que a comunidade de aprendizagem trabalhada foi, por sua vez, constituída por educadores, pode-se ainda aquilatar junto aos participantes as suas próprias e específicas considerações relativas ao significado do ensino de Ciência do Sistema Terra para a elaboração e planificação de atividades de ensino de Ciências. Verificou-se que estes passaram a reconhecer o caráter singular da geologia como integradora dos saberes de Ciências que cumpre ensinar na educação básica, e que a partir da formação alcançada se sentiram mais capacitados e motivados paro o exercício da tarefa de educadores em Ciências.

DISCUSSÃO Não obstante o desenvolvimento da Ciência do Sistema Terra venha provendo novos e crescentes conhecimentos relativos ao melhor e mais racional uso dos recursos naturais do planeta, isso só não basta para que se construa uma condição de sustentabilidade para o desenvolvimento. É preciso que a mudança de modelos desenvolvimentistas se dê, e esta só poderá ocorrer quando a sociedade global se incumbir da responsabilidade e do compromisso de alterar suas práticas, seus costumes e sua cultura extrativista, em prol de uma cultura ética e solidária.

Nessa cultura inovadora, a sustentação da vida se processa sob o reconhecimento de diferenciais de qualidade e não mediante a busca incessante de lucros e riquezas. Nessa ótica, pode-se considerar que tal mudança de paradigma constitua mesmo uma utopia e que o conceito de sustentabilidade seja insustentável, como insistem alguns autores.

Esse é o ponto em que mais claramente o conhecimento da Ciência do Sistema Terra pode constituir referencial privilegiado para a construção da cultura de sustentabilidade. Ao se constatar a natureza cíclica, e de constante busca de equilíbrio dinâmico, que se opera em toda a matéria planetária - aspecto que a natureza sistêmica da Ciência da Terra comporta de forma incontestavelmente superior - as perspectivas de mudança emergem como condição natural e essencial para a busca constante do equilíbrio.
Nesse sentido é que o conhecimento da Ciência do Sistema Terra deve ser mais bem explorado em práticas educacionais de ensino-aprendizagem. Os saberes geológicos podem e devem constituir referencial curricular multi, trans, pluri e interdisciplinar, capaz de agregar valor intrínseco ao ensino efetivo, por proporcionar a formação integral do cidadão planetário.

A construção deste salto conceitual e cognitivo no ensino de Ciências requer forte compromisso dos geocientistas, para profusão do ensino da Ciência do Sistema Terra no âmbito da sociedade globalizada. Neste sentido ganha reforço e acuidade a atenção à formação dos profissionais de educação básica. Responsáveis pela multiplicação e difusão dos saberes escolares, estes profissionais serão artífices de uma cultura inovadora. Deverão, compreender a complexidade dos conceitos, processos e materiais geológicos a fim de orientar a prática pedagógica interdisciplinar que valorize a compreensão da interdependência existente entre os componentes do Sistema Terra. Assim poderão conduzir ao desenvolvimento de uma educação compromissada com a vida e com um desenvolvimento que possa ser sustentável.

Marques \& Praia (2001, p. 12) auxiliam a expor o potencial e a amplitude do compromisso que a Educação em Geociências tem a desempenhar na sociedade atual e futura. A preservação do Planeta Azul, planeta vivo e dinâmico, é a preocupação primeira, exigindo uma mudança cultural e de mentalidades que é preciso desde já levar por diante, marcadamente de índole educacional. O currículo, para além da sua forte integração e transdisciplinaridade, transfere, rompe mesmo, com a idéia de um ensino estritamente disciplinar, de sentido instrucional, passando agora a ganhar novos sentidos na lógica de uma Educação Para Todos, de qualidade, em que a responsabilidade individual e social são exigências constantes. Claramente, o que está em jogo, no limiar do século XXI, é um novo compromisso com a Terra - planeta de rara beleza - e do papel que a Educação em Geociências pode e deve aí desempenhar.

COMENTÁRIOS FINAIS Na relação dinâmica do ensino-aprendizagem, o ensino de Geociências é essencial para o desenvolvimento cultural do cidadão terreno, uma vez que as contribuições das Geociências ao desenvolvimento cognitivo promovem a consciência do indivíduo planetário, ainda que esta envolva alto grau de abstração.

O uso de informações geológicas de caráter regional e local constitui forte elo integrador da aprendizagem. Convida os aprendizes/participante à reflexão, porque lhes mostra a realidade do local onde vivem, estimulando a consciência reflexiva de cada um. Enfim, apresentam razões e evidenciam meios de inovar as práticas letivas, o tratamento interdisciplinar e transdisciplinar de temas relacionados a recursos naturais. Finalmente, o envolvimento pessoal com questões da coletividade despertará certo senso comum de solidariedade. 
Os participantes desse movimento dinâmico sentem-se motivados a inovar criativamente e a experimentar mudanças de postura, de engajamento social e de compromisso humano, alimentando a percepção de que mudanças são possíveis mesmo em curto prazo.

A consciência propiciada pela inserção ativa de temas geológicos no ensino permite evocar o papel multiplicador da educação, ao mesmo tempo em que resgata sentimentos de segurança, confiança, motivação, auto-estima, autonomia, liberdade, interesse pela educação continuada e permanente, reconhecimento da própria capacidade de intervir, vivência colaborativa, satisfação pessoal e senso comum de integrar a coletividade terrena que se pretende sustentável.

Em síntese, da experiência de aplicação do conhecimento de Ciência do Sistema Terra no ensino, sobressaem vários indicadores de terem sido alcançados objetivos inerentes a uma educação voltada para a reflexão crítica, desenvolvimento de valores sociais e éticos relevantes e construção de cidadania.

\section{Referências}

AMERICAN ASSOCIATION FOR THE ADVANCEMENT OF SCIENCE (AAAS). 1989. Science for All Americans Online. Disponível em: http://www.project2061. org/publications/sfaa/online/sfaatoc.htm. Acesso em 21.12.2005.

Anguita Virela F. 1994. Geología, ciencias de la Tierra, ciencias de la naturaleza: paisaje de un aprendizaje global. Enseñanza de las Ciencias, 12(1):15-21.

Berbert C.O. 2007. 2008 - O Ano Internacional do Planeta Terra. Brasília, SIGEP. Disponível em: http://www.unb. br/ig/sigep/destaques/AIPT.pdf. Acesso em 26.09.2007.

Bordieu P. 2003. Os usos sociais da ciência. Por uma sociologia clínica do campo científico. Trad. D. B. Catani. São Paulo: Ed. UNESP, 86p.

Brasil. Ministério da Educação. Secretaria de Educação Média e Tecnológica. 1999. Parâmetros Curriculares Nacionais: Ensino Médio. Brasília: Ministério da Educação, 364 p.

Cachapuz A.F., Praia J.F.M., Jorge M.P. 2002. Ciência, Educação em Ciência e Ensino das Ciências. Lisboa: Ministério da Educação, Temas de investigação, 263, $53 p$.

Carneiro C.D.R., Barbosa R. 2005. Geo-escola: disseminação de conteúdos de Geociências por meio do computador para docentes de Ciências e Geografia no Nível Fundamental em Jundiaí-Atibaia, SP. Geologia USP Série Didática, Publ. Espec., 3:71-82.

Carneiro C.D.R., Barbosa R., Piranha J.M. 2007. Bases teóricas do Projeto Geo-Escola: uso do computador para ensino de Geociências. Rev. Bras. Geoc., 37(1):90-100.

Carneiro C.D.R. \& Gonçalves P.W. 2006. Earth System Science Teaching for Geology and Geography Undergraduate Students in Campinas, Brazil. In: Intern. Conf. on geosc. Education, 5, Baireuth, Germany, Conf Proc... Baireuth: GeoSciEd V Org. Committee/IGEO.

Carneiro C.D.R., Gonçalves P.W., Negrão O.B.M., Cunha C.A.L. 2005. Ciência do Sistema Terra e o entendimento da "máquina" planetária em que vivemos. Belo Horizonte. Geonomos, 13(1):11-18.

Certeau M. 2001. A cultura no plural. 2. ed. Trad.: Enid Abreu Dobránszky. Campinas: Papirus, 253 p. (Col. Travessia do século).

Compiani M. 2005. Geologia/Geociências no ensino fundamental e a formação de professores. Geologia USP Série Didática, Publ. Espec., 3:13-30.
Cordani U.G. 1995. As Ciências da Terra e a mundialização das sociedades. Estudos Avançados USP, 9(25):13-27.

Cordani U.G. 2000. As Ciências da Terra na sociedade contemporânea. Cadernos IG/UNICAMP., 8(1-2):22-35.

Figueiredo B.R. 2007. O Ano Internacional do Planeta Terra. Campinas, Jornal da Unicamp, 364:2. (2 a 15 de julho de 2007).

Forquin J.C. 1993. Escola e Cultura - as bases sociais e epistemológicas da conhecimento escolar. Trad. Guacira Lopes Louro. Porto Alegre: Artes Médicas, 208p.

Freire P. 1992. Educação permanente e as cidades educativas. In: Freire P. 2001. Política e Educação. São Paulo: Cortez, p.16-26.

Frodeman R.L. (ed.) 2000. Earth matters: the Earth Sciences, phylosophy and the claims of community. Upper Saddle River, Prentice Hall, 209p.

Konder L. 2001. Fazendo uma tessitura nas conversas entre professores e professoras. In: Chassot A. \& Oliveira R.J. (orgs.) Ciência, ética e cultura na educação. São Leopoldo: Unisinos, p. 25-26.

Lopes A.R.C. 2001. Currículo, conhecimento e cultura: construindo tessituras plurais. In: Chassot A. \& Oliveira R.J. (orgs.) Ciência, ética e cultura na educação. São Leopoldo: Unisinos, p. 31- 47.

Mackenzie F.T. \& Mackenzie J.A. 1995. Our changing planet: an introduction to Earth system science and global environmental change. Englewood Cliffs: Prentice Hall.

Marques L. \& Praia J. (coords.) 2001. Geociências nos currículos dos ensinos básico e secundário. Aveiro: Univ. Aveiro, 355p.

Mayer V. J. (ed.) 2002. Global Science Literacy. Dordrecht: Kluwer Acad. Publ.

Morin E. 2002. Os sete saberes necessários à educação do futuro. Trad. Catarina Eleonora F. da Silva \& Jeanne Sawaya. 6 ed., São Paulo: Cortês, 118p.

Morin E. 2003. O método 5: a humanidade da humanidade. Trad. Juremir Machado da Silva. 2 ed., Porto Alegre: Sulina, 312p.

Morin E. \& Kern A.B. 2002. Terra - Pátria. Trad. Paulo Azevedo Neves da Silva. 3 ed. Porto Alegre: Sulina, $181 \mathrm{p}$.

Orion N. 2001. A educação em Ciências da Terra. Da teoria à prática-implemantação de novas estratégias de ensino em diferentes ambientes de aprendizagem. In: Marques L., Praia J. (coords.) Geociências nos currículos dos en- 
sinos básico e secundário. Aveiro: Univ. Aveiro, p. 93114.

Perrenoud P. 1999. Construir as competências desde a escola. Trad. Bruno Charles Magne. Porto Alegre: Artes Médicas Sul, 90p.

Piranha J.M. 2006. O ensino de geologia como instrumento formador de uma cultura de sustentabilidade: o Projeto Geo-Escola em São José do Rio Preto, SP. Tese Doutoramento, Campinas, Inst. Geoc., Unicamp, 105p. (2 CD-ROMs incl.).

Piranha J.M. \& Carneiro C.D.R. 2007. O ensino de geologia como componente da cultura profissional docente. In: DGAE/IG/Unicamp, Simpósio de Pesquisa em Ensino e História de Ciências da Terra, 1, e Simpósio Nacional sobre Ensino de Geologia no Brasil, 3, Campinas, Anais, p. 125-131. (CD-ROM, 051.pdf).

Piranha J.M. \& Carneiro C.D.R. (no prelo). O Módulo São José do Rio Preto do Projeto Geo-Escola - uma experiência educacional diferenciada. Revista Brasileira de Geociências.

Piranha J.M., Pacheco A., Carneiro C.D.R., Rebouças A.C., Antonello S.L. 2004. Recursos Hídricos e Desenvolvimento. Diagnóstico básico preliminar do município de São José do Rio Preto. São José do Rio Preto: UNESP, USP e UNICAMP. (1 CD-ROM: Windows $\mathrm{XP}$ ).

Potapova M.S. 1968. Geology as an historical science of nature. In: Interaction of sciences in the study of the Earth. Progress, Moscow. 117-126. [Trad.] Geologia como uma ciência histórica da Natureza. Trad: Conrado Paschoale. Terrce Didatica, 3(1):86-90. Disponível em: http://www. ige.unicamp.br/terraedidatica/. Acesso em 2.04.2009.

Praia J.F.M., Gil-Pérez D., Vilches A. 2007. O papel da Ciência na Educação para a cidadania. Ciência\& Educação, 13(2):141-156.

Rios T.A. 2002. Compreender e ensinar: por uma docência da melhor qualidade. 3 ed. São Paulo: Cortês, 158 p.

Schaff A. 1995. A Sociedade Informática: as conseqüências sociais da segunda revolução industrial. 4 ed. São Paulo: Ed. UNESP / Brasiliense, 157p.

Sowell T. 2007. A fraude do aquecimento global. s.l. MidiaSemMascara.org. Disponível em: http://www.midiasemmascara.com.br/artigo.php?sid=5729. Acesso em 19.02.2008.

UNESCO. United Nations Educational, Scientific and Cultural Organization. 1999. Ciência para o século XXI - Um novo Compromisso. Apud: Cachapuz A.J. Praia \& Jorge M. 2002. Ciência, educação em ciência e ensino das ciências. Lisboa: Ministério da Educação, Temas de investigação, 263, 53p.

UNESCO. United Nations Educational, Scientific and Cultural Organization. 2006. Iniciativa de Alfabetización para el Potenciamento 2005-2015. Perspectivas y Estrategias. 2a Ed. Disponivel em: http://unesdoc.unesco.org/images/0014/001411/141177s.pdf. Acesso em 17 fev. 2009.

Valle L. do. (org). 2000. O mesmo e o outro da cidadania. Rio de Janeiro: DP\&A, 144p. (Col. O Sentido da Escola. 15, Cidadania e escola pública, p.13-32).

Veiga-Neto A. 2002. Espaço e currículo. In: Lopes A.R.C., Macedo E. (orgs.) 2002. Disciplinas e integração curricular: história e políticas. Rio de Janeiro: DP\&A., p. 201-220.

Williams Jr. R.S. 2000. The modern Earth narrative: natural and human history of the Earth. In: Frodeman R.L. (ed.) 2000. Earth matters: the Earth Sciences, phylosophy and the claims of community. Upper Saddle River: Prentice Hall, p. 35-49. (Chapter 4).

Manuscrito ID 11103

Submetido em 14 de abril de 2008 Aceito em 16 de fevereiro de 2009 